\title{
Editorial
}

e-Neuroforum 2015 - 6:59-62

DOI 10.1007/s13295-015-0012-0

Published online: 31 July 2015

c) Springer-Verlag Berlin Heidelberg 2015

\author{
Christine R. Rose ${ }^{1}$. Frank Kirchhoff ${ }^{2}$ \\ ${ }^{1}$ Institute of Neurobiology, Heinrich Heine University Düsseldorf, Düsseldorf, Germany \\ ${ }^{2}$ Molecular Physiology, Center for Integrative Physiology and Molecular \\ Medicine (CIPMM), University of Saarland, Homburg, Germany
}

\section{Glial heterogeneity: the increasing complexity of the brain}

"How does the brain work?" is one of the most frequently asked questions. By and large, the human brain consists of approximately 160 billion cells that mainly represent two types, classified as neurons and glia, each contributing about $50 \%$ to the total cell number. Modern imaging techniques such as functional magnetic resonance imaging (fMRI) or diffusion-tensor imaging (DTI) show us many functional details of our brain's plastic activities and have provided exciting new insights of how and where the brain processes specific information (• Fig. 1a). Interestingly, neither fMRI nor DTI are mechanistically based on the electrical activity of neurons, classically thought to be exclusively responsible for information processing in the brain. Instead, these techniques enable the visualization of brain activity based on changes of cerebral blood flow, i.e. the oxygen content supplied by blood capillaries, or by anisotropic water diffusion. The cellular building blocks of the smallest fMRI and DTI signals have already been identified as the neurovascular unit and the myelin-axon unit, respectively ( $\bullet$ Fig. $1 \mathbf{b}$ and c). A single fMRI voxel integrates the oxygen consumption of several cell types with vascular, glial and neuronal origin: endothelial cells, neutrophils, pericytes, astrocytes, microglia, NG2 glia, oligodendrocytes and neurons. The myelin-axon unit that gives rise to the DTI signal appears much less complicated: neuronal fiber tracts, the axons, are surrounded by the insulating and support-providing myelin sheaths of the oligodendrocytes. Both imaging techniques take thus advantage of the strategic positions of glial cells which enable them to power neurons and to maintain long-range connections, highlighting the prominent role of neuroglia in neuronal performance.

The two-dimensional space of histological or vital brain sections already demonstrated that cells were organized in functional and morphological networks. Among these are the columnar modules of the cortex that contribute to sensory integration and cognition, the layers of the hippocampus involved in learning and memory, the rhythmic centers of the brain stem which regulate breathing, or the cerebellar circuits responsible for fine-tuning motor coordination. While excitatory and inhibitory neurons are the main relay stations for the input, processing and output of electrical signals, the macroglial cells execute quite different tasks. Astrocytes are polarized cells that represent a bridge between blood vessels and neurons. They take up nutrients from the blood, metabolize them and provide them to neurons. Astrocytes also regulate extracellular ion and transmitter homeostasis from the socalled "tri-partite" synapse where they are in direct contact with neuronal synapses. Furthermore, by secreting transmitters and peptide hormones, they can directly modulate synaptic transmission. Oligodendrocytes insulate neuronal axons with a lipid-rich structure, the myelin sheath, to accelerate action potential propagation and to electrically insulate axons. Recent data has additionally demonstrated that oligodendrocytes metabolically support axons, the long-range links of neural circuits. Glial cells expressing the proteoglycan NG2 (NG2 glia) are a relatively novel class of macroglia and were originally identified as oligodendroglial progenitor cells, but appear to represent a more versatile cell reservoir in the adult brain.

Present-day research provides compelling evidence that a neuron-centered picture of the brain is way too simplistic, indicating that each class of glial cells is much more diverse than commonly thought. Glial cells appear to have distinct physiological properties in different brain regions, at different developmental stages and at different activity levels of the organism. These observations suggest that functional specializations of glia might have developed to meet the specific requirements of distinct networks which might as such be critical determinants of brain activity. This new concept will change the way we think about brain function and put glial cells into an even more prominent focus of attention.

Astrocytes are probably the most versatile class of neuroglia. Functionally positioned between the pia mater, blood vessels and neuronal synapses, they display a plethora of properties. Astrocytes contribute to the blood-brain barrier [3], take up nutrients from the blood, metabolize them and provide energy substrates to neurons [26]. They link neuronal activity to blood circulation [2, 15], promote synapse formation $[5,8]$, and determine the properties of the extracellular matrix $[9,16,27]$. Furthermore, they regulate extracellular ion and transmitter levels thereby regulating synaptic transmission. Last but not least, astrocytes secrete compounds which modulate neurotransmission $[1,22]$. This impressive list demonstrates via how many routes astrocytes interact with neurons and influence brain activity. Astrocytes must be particular- 

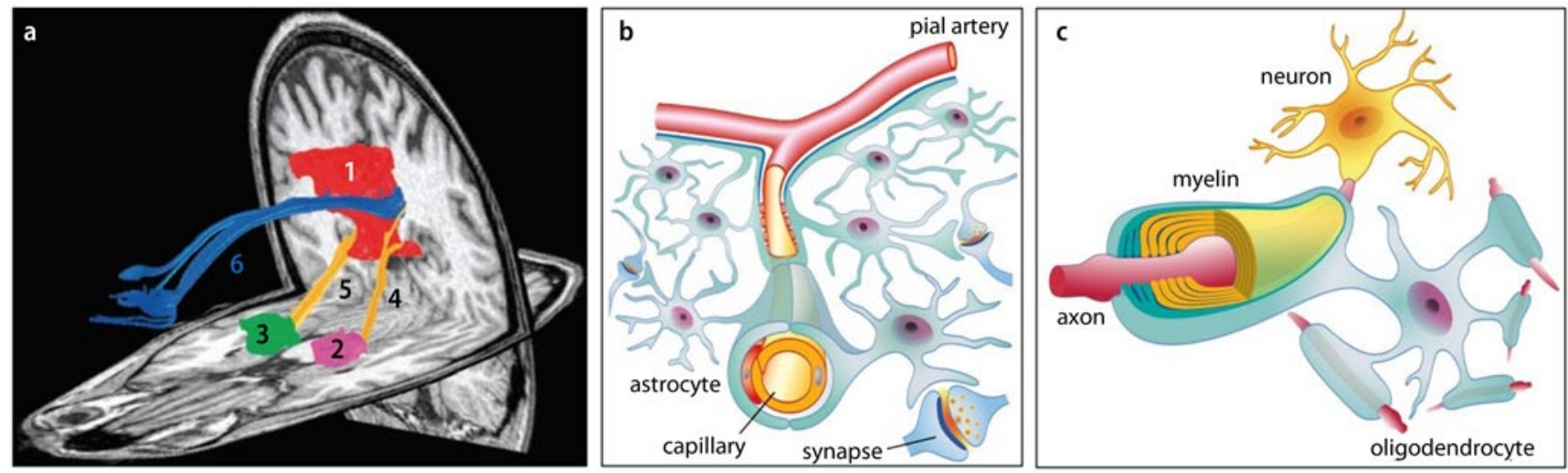

Fig. 1 Modern brain imaging techniques are mechanistically based on activity of macroglial cells. a Functional magnetic resonance imaging $(F M R I)$ is able to visualize different functional units (1-3) of the brain in its idle mode (default mode network). A variant of $\mathrm{fMRI}$, diffusion tensor imaging (DTI) can selectively visualize connecting fibre tracts between these centres (4-6). b The cellular basis of the fMRI signal is the change in oxygen levels in the neurovascular unit composed of capillaries, astrocytes and neurones. $\mathbf{c}$ The axon-myelin unit of fibre tracts causes anisotropic water diffusion that gives rise to DTI signals. Figure A modified from [13]

ly tailored to fulfil these functions and be able to adapt to the developmental stage, the brain region and the activity phases. Indeed, numerous examples of glial heterogeneity exist. This is especially conspicuous in the morphological specialization of astrocytes (- Fig. 2). In some regions such as the cerebellar cortex and the retina, they exhibit a radial orientation. In contrast, astrocytes in the cortex or hippocampus extend processes in all directions displaying a star-like appearance, while those of the white matter are less frequently branched and largely lack thin membrane protrusions. Not surprisingly, first profiling studies of astrocytes isolated from different brain regions display substantial differences in gene expression $[4,7,23]$. These include cell surface glycoproteins and components of the extracellular matrix, ion channels, neurotransmitter receptors and transporters, connexins, Eph receptors, and many more [10, $20,28]$. More recent studies show that astroglia sense and compute neuronal activity to feed back to neurones, thereby even modulating the most visible brain output, the behaviour. Astroglial cannabinoid receptors in the hippocampus, for example, are involved in the acquisition of spatial working memory [14], and in the cerebellum, Bergmann glial AMPA receptors are important determinants of fine motor coordination [25].

The second class of macroglia, the oligodendrocytes, are the myelin-forming cells of the CNS. A single oligodendro- cyte enwraps up to 50 axons, and myelinating segments can vary in length from 50 to $400 \mu \mathrm{m}$. Their morphological heterogeneity has already been described by RioHortega, who distinguished four types. In white matter fiber tracts such as the optic nerve or the corpus callosum, axons are mainly oriented in parallel, and so are the processes of the oligodendrocytes. In contrast, in grey matter regions where axons traverse the parenchyma irregularly, oligodendroglial processes point into all directions. The functional characterization of oligodendroglial heterogeneity is still in its infancy. They are equipped with a variety of receptors to sense the extracellular level of transmitters released by neurones [17]. As a consequence, myelination is regulated by neuronal activity, but is also determined by axon diameter. In addition to their role in myelination, recent studies highlight the important role of oligodendrocytes in supporting axons also metabolically $[11,19]$.

NG2 glial cells constitute less than ten percent of glial cells in the developing and adult CNS [6]. They have originally been identified by the expression of the chondroitinsulfate proteoglycan NG2, and functionally been characterized as oligodendrocyte progenitor cells. Recent studies demonstrate that outside of neurogenic niches, NG2 cells are the most proliferative cells of the adult CNS. NG2 glial cells are the only glial cells directly innervated by neurons. While in the hippocampus and cerebellum NG2 cells receive both glutamatergic and GABAergic input, NG2 cells in the medial nucleus of the trapezoid body only receive excitatory glutamatergic synaptic input in parallel to the Calyx of Held [21]. The neuron-glia synapses even persist during cell division. Although all NG2 cells can develop into oligodendrocytes, there exist strong differences between white and grey matter. While in the corpus callosum, almost two third of NG2 glia become oligodendrocytes, in the cortex $90 \%$ remain NG2 glia. Cell proliferation was suggested to be regulated by voltage-gated sodium and potassium channels heterogeneously expressed on NG2 glia during differentiation [12, 18].

The Deutsche Forschungsgemeinschaft acknowledges the demand for further research on the heterogeneity and funds the special priority program SPP 1757 "Functional specializations of neuroglia ascritical determinants of brain activity". The Priority Program will pave the way for a better understanding of the molecular and cellular role of glia in brain pathologies that is urgently needed to develop novel, more customized and targeted strategies for the treatment of brain injury and disease.

In this special issue of Neuroforum members of the SPP 1757 will present recent highlights of glia research addressing the heterogeneity of astrocytes (Christian Henneberger), NG2 glia (Dirk Dietrich and Christian Steinhäuser) and oligodendrocytes (Leda Dimou and Michael Wegner). These reviews will be complement- 


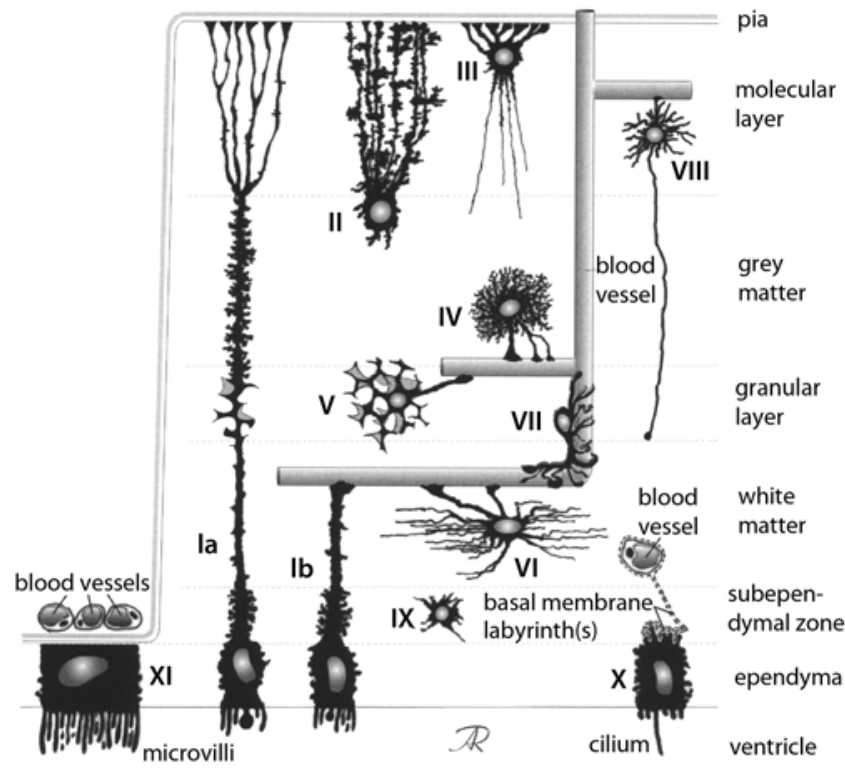

Fig. $2 \Delta$ Heterogeneity of human astroglia. Semi-schematic survey of the main types of astroglia and related glial cells, and their localization in different layers/specialized regions of the human brain. I: tanicyte (a: pial; b: vascular); II: radial astrocyte (Bergmann glial cell); III: marginal astrocyte; IV: protoplasmic astrocyte; V: velate astrocyte; VI: fibrous astrocyte; VII: perivascular astrocyte; VIII: inter-laminar astrocyte; IX: immature astrocyte/glioblast; $X$ : ependymocyte; XI: choroid plexus cell. From: Reichenbach and Wolburg [24]

ed by an article of Daniela Dieterich and Moritz Rossner who describe novel highthroughput approaches with significant impact for the identification of cellular specializations in the brain and among glial cells. The SPP 1757 moreover will serve as a platform to enhance inter-lab communication not only at the national, but also at the international level. Especially strong ties have been established with glial research colleagues in Japan. Kazuhiro Ikenaka will describe the Japanese program to foster glial research.

\section{Corresponding addresses}

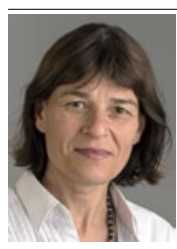

C.R. Rose

Institute of Neurobiology

Heinrich Heine University

Düsseldorf

Universitätsstr. 1; Building

26.02.00, 40225 Düsseldorf

rose@uni-duesseldorf.de

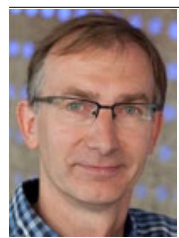

\section{F. Kirchhoff}

Molecular Physiology, Center for Integrative Physiology and Molecular Medicine (CIPMM) University of Saarland Building 48, 66421 Homburg frank.kirchhoff@uks.eu
Christine R. Rose Diploma in Biology (University of Konstanz); PhD 1990-1993 University of Kaiserslautern (Dept. of General Zoology, Prof. J. Deitmer); Postdoctoral Fellow (DFG Fellowship) at the Dept. of Neurology, Yale University School of Medicine (Bruce Ransom and Steve Waxman). 1997-1999 Research Assistant at the Institute of Physiology (University of Saarland, Homburg; Prof. A. Konnerth), 1999-2003: Research Assistant at the Institute of Physiology TU/ LMU Munich (A. Konnerth); 2001: Habilitation in Physiology (LMU Munich), 2003-2005 Heisenberg Fellow of the DFG DFG. Since 2005: Director of the Institute of Neurobiology (University Düsseldorf). Since 2012 Subject Reviewer of the DFG.

Frank Kirchhoff 1981-1985: Diploma in Biochemistry at the University of Hannover; 1986-1990 PhD University Heidelberg (Institute of Neurobiology, Prof. M. Schachner); 1991-1994 Postdoktoral Fellow (Institute of Neurobiology, Prof. Helmut Kettenmann); 1995-1999 Max Delbrück Center for Molecular Medicine Berlin (Cellular Neurosciences, Prof. H. Kettenmann), 1997 Habilitation in Biochemistry at the Free University of Berlin; 2000-2008 research group leader at the Max Planck Institute of Experimental Medicine (Neurogenetics, Prof. K.-A. Nave). Since 2009 University Professor (Molecular Physiology, University of Saarland, Homburg).

\section{References}

1. Araque A, Carmignoto G, Haydon $\mathrm{PG}$, Oliet $\mathrm{SH}$, Robitaille R, Volterra A (2014) Gliotransmitters travel in time and space. Neuron 81:728-739

2. Attwell D, Buchan AM, Charpak S, Lauritzen M, Macvicar BA, Newman EA (2010) Glial and neuronal control of brain blood flow. Nature 468:232243
3. Ballabh $P$, Braun $A$, Nedergaard $M$ (2004) The blood-brain barrier: an overview: structure, regulation, and clinical implications. Neurobiol Dis 16:113

4. Beckervordersandforth $R$, Tripathi P, Ninkovic J, Bayam E, Lepier A, Stempfhuber B, Kirchhoff F, Hirrlinger J, Haslinger A, Lie DC, Beckers J, Yoder B, Irmler M, Gotz M (2010) In vivo fate mapping and expression analysis reveals molecular hallmarks of prospectively isolated adult neural stem cells. Cell Stem Cell 7:744-758

5. Chung WS, Allen NJ, Eroglu C (2015) Astrocytes Control Synapse Formation, Function, and Elimination. Cold Spring Harb Perspect Biol a020370

6. Dimou L, GalloV (2015) NG2-glia and their functions in the central nervous system. Glia 63:14291451

7. Doyle JP, Dougherty JD, Heiman M, Schmidt EF, Stevens TR, Ma G, Bupp S, Shrestha P, Shah RD, Doughty ML, Gong S, Greengard P, Heintz N (2008) Application of a translational profiling approach for the comparative analysis of CNS cell types. Cell 135:749-762

8. Eroglu C, Barres BA (2010) Regulation of synaptic connectivity by glia. Nature 468:223-231

9. Faissner A, Pyka M, Geissler M, Sobik T, Frischknecht R, Gundelfinger ED, Seidenbecher C (2010) Contributions of astrocytes to synapse formation and maturation - potential functions of the perisynaptic extracellular matrix. Brain Res Rev 63:2638

10. Freeman MR (2010) Specification and morphogenesis of astrocytes. Science 330:774-778

11. Fünfschilling U, Supplie LM, Mahad D, Boretius $S$, Saab AS, Edgar J, Brinkmann BG, Kassmann CM, Tzvetanova ID, Möbius W, Diaz F, Meijer D, Suter U, Hamprecht B, Sereda MW, Moraes CT, Frahm J, Goebbels S, Nave KA (2012) Glycolytic oligodendrocytes maintain myelin and long-term axonal integrity. Nature 485:517-521

12. Gallo V, Zhou JM, Mcbain CJ, Wright P, Knutson PL, Armstrong RC (1996) Oligodendrocyte progenitor cell proliferation and lineage progression are regulated by glutamate receptor-mediated $\mathrm{K}+$ channel block. J Neurosci 16:2659-2670

13. Greicius MD, Supekar K, Menon V, Dougherty RF (2009) Resting-state functional connectivity reflects structural connectivity in the default mode network. Cereb Cortex 19:72-78

14. Han J, Kesner P, Metna-Laurent M, Duan T, Xu L, Georges F, Koehl M, Abrous DN, Mendizabal-Zubiaga J, Grandes P, Liu Q, Bai G, Wang W, Xiong L, Ren W, Marsicano G, Zhang X (2012) Acute cannabinoids impair working memory through astroglial CB1 receptor modulation of hippocampal LTD. Cell 148:1039-1050

15. Haydon PG, Carmignoto G (2006) Astrocyte control of synaptic transmission and neurovascular coupling. Physiol Rev 86:1009-1031

16. Jones EV, Bouvier DS (2014) Astrocyte-secreted matricellular proteins in CNS remodelling during development and disease. Neural Plast 2014:321209

17. Karadottir R, Attwell D (2007) Neurotransmitter receptors in the life and death of oligodendrocytes. Neuroscience 145:1426-1438

18. Karadottir R, Hamilton NB, Bakiri Y, Attwell D (2008) Spiking and nonspiking classes of oligodendrocyte precursor glia in CNS white matter. Nat Neurosci 11:450-456 


\section{Editorial}

19. Lee $Y$, Morrison $B M$, Li Y, Lengacher S, Farah MH, Hoffman PN, Liu Y, Tsingalia A, Jin L, Zhang PW, Pellerin L, Magistretti PJ, Rothstein JD (2012) Oligodendroglia metabolically support axons and contribute to neurodegeneration. Nature 487:443448

20. Matyash V, Kettenmann H (2010) Heterogeneity in astrocyte morphology and physiology. Brain Res Rev 63:2-10

21. Müller J, Reyes-Haro D, Pivneva T, Nolte C, Schaette R, Lubke J, Kettenmann H (2009) The principal neurons of the medial nucleus of the trapezoid body and $\mathrm{NG2}(+)$ glial cells receive coordinated excitatory synaptic input. J Gen Physiol 134:115-127

22. Perea G, Navarrete M, Araque A (2009) Tripartite synapses: astrocytes process and control synaptic information. Trends Neurosci 32:421-431

23. Pinto L, Mader MT, Irmler M, Gentilini M, Santoni F, Drechsel D, Blum R, Stahl R, Bulfone A, Malatesta P, Beckers J, Gotz M (2008) Prospective isolation of functionally distinct radial glial subtypes-lineage and transcriptome analysis. Mol Cell Neurosci 38:15-42

24. Reichenbach A, Wolburg $H$ (2005) Astrocytes and ependymal glia. In: Kettenmann $\mathrm{H}$ \& Ransom BR (eds) Neuroglia, 2nd edn. Oxford University Press, New York

25. Saab AS, Neumeyer A, Jahn HM, Cupido A, Simek AA, Boele HJ, Scheller A, Le Meur K, Gotz M, Monyer $\mathrm{H}$, Sprengel $\mathrm{R}$, Rubio ME, Deitmer JW, De Zeeuw $\mathrm{Cl}$, Kirchhoff F (2012) Bergmann glial AMPA receptors are required for fine motor coordination. Science 337:749-753

26. Suzuki A, Stern SA, Bozdagi O, Huntley GW, Walker RH, Magistretti PJ, Alberini CM (2011) Astrocyteneuron lactate transport is required for long-term memory formation. Cell 144:810-823

27. Wiese S, Karus M, Faissner A (2012) Astrocytes as a source for extracellular matrix molecules and cytokines. Front Pharmacol 3:120

28. Zhang Y, Barres BA (2010) Astrocyte heterogeneity: an underappreciated topic in neurobiology. Curr Opin Neurobiol 20:588-594 